\title{
A Modern Requirement
}

Herbert Walther, who chairs the EPS-10 General Conference (Seville; 9 - 13 September 1996) International Programme Committee, reminds us of the importance of general meetings.

In recent years the physics community has become split over its opinion of the value of major conferences which attempt to cover large areas, or even the entire breadth of the discipline of physics. Indeed, the tendency is towards smaller, more specialized meetings where colleagues in a certain field gather to discuss their work with people who can usually provide the best advice for overcoming the problems associated with the particular field. There, in the midst of like-minded people, life is simpler and everyone feels at home in a family-like atmosphere. However, one important aspect is missing in such meetings namely, the view across the fence providing information on the recent, state-of-the-art developments in fields other than one's own. This more general information is very important, especially for young people.

There are several reasons why an occasional thorough survey of the whole is one of the requirements for today's physicist. First, modern physics is developing so rapidly and in so many directions that it is impossible for a single person to stay abreast of all of the results in all of today's journals. Second, a physicist will generally change field of work at least once, if not several times, during a career, so some knowledge of other fields is occasionally a necessity. Third, the different branches of physics fertilise each other, especially when the methods used in a given field are found to be applicable to the solution of problems in other areas. It often occurs that the best clues for solving a problem come from research in a completely different field. Moreover, such cross-fertilization often results in the emergence of the most innovative ideas.

The objectives of the EPS General Conference Trends in Physics are to survey most of the recent major developments in physics and to provide an opportunity to discuss important trends for the future. The International Programme Committee for the next event - EPS-10 in Seville in September - aimed to obtain the very best

Herbert Walther is Professor of Physics at Munich University and Director of the Max-Planck Institute for Quantum Optics, Garching. speakers. Proposals were sought from the various EPS Divisions and Interdivisional Groups and discussed on two separate occasions by the committee. The final selection gave the highest priority to those themes which were judged as capable of capturing the broadest general interest amongst the physics community.

As can be seen from the preliminary scientific programme published in last month's News from EPS [EN 27 (1996) 38], there will be plenary talks covering topics ranging from current issues in particle physics to very topical problems in solidstate physics, such as quantum transport in nanostructures and recent results in polymer physics. Environmental problems as well as physics aspects of biology and medicine will also be addressed.

Besides the plenary talks there will be parallel symposia. These aim to cover subfields which are rapidly developing so they may tend to be a little speculative in nature, or in need of a broader viewpoint owing to the many associated aspects. The symposia, limited in duration to some two and a half hours, will generally be split up into a series of invited talks interspersed with discussion. The selection of the speakers is the responsibility of the symposium organizer, and most symposia will be accompanied by a poster session to provide a deeper perspective. Prominent among the topics which have been chosen for the symposia are fullerenes and nanotubes, quantum communication and BoseEinstein condensation. Furthermore, several special topics have been integrated into the symposia because they are widely discussed by the general public. These include energy policies and their ecological impact, university-industry relations and physics education (the last being of particular interest to physics teachers). One item has been included because it is of special interest to younger colleagues, namely a panel discussion on employment opportunities. Physicists from both industrial companies and research institutions will be asked to express their views on this important problem, for in addition to the extensive discussion of the issue at the national level we need new ideas and solutions at the wider European scale.

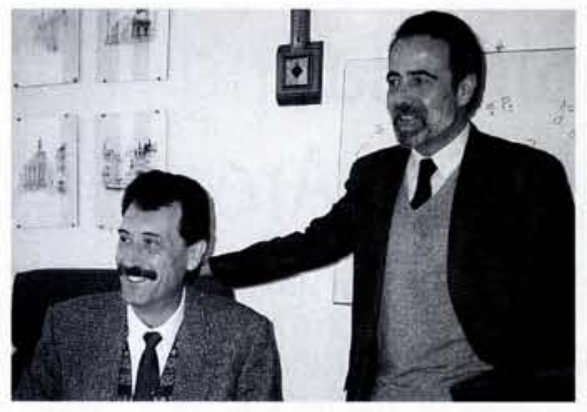

The 1996 EPS-10 General Conference Trends in Physics is co-chaired by M. Lozano Leyva from Seville, on the left, and by C.M. Ferreira from Lisbon, on the right. It is jointly organized by the Royal Spanish Physical Society and by the Portuguese Physical Society. His Highness the King of Spain has agreed to be a member of the Honourary Committee which includes several other eminent personalities from Spain and Portugal, notably Spain's Minister of Science and Education and Portugal's Minister of Science and Technology.

A meeting requires a pleasant ambiance as well as an excellent scientific programme. In this respect, Seville is one of the best places to be found in Europe. As the capital of Andalucía it offers considerable historical and cultural attractions resulting from the interesting interaction of its Muslin, Jewish and Christian pasts. A special event will be an exhibition of scientific instruments from the Baroque era. Sponsored by the Portuguese government, it met with a huge success when displayed in Liège two years ago. So attending the EPS-10 conference will be a rewarding experience in many respects. The programme committee and the local organizing committees have done their utmost to prepare an excellent meeting in a friendly and stimulating setting. We all hope to see you in Seville in September.
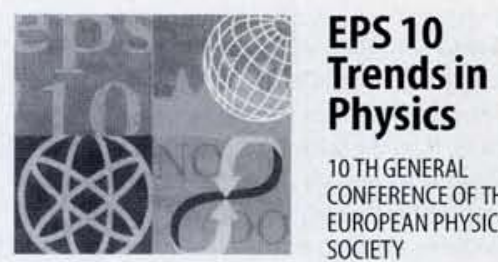

10 THGENERAL CONFERENCE OF THE EUROPEAN PHYSICAL SOCIETY

9-13 September 1996 - Seville, Spain

Organizing Secretariat and Further Information PROCONSUR, Avda. San Francisco Javier 14, 4 th Floor, E-41018 Seville, Spain

Tel +34-5-4922755 - Fax +34-5-4923015

E-mail eps10@cica.es

Early registration before 15 June 1996

Fees (in PTAS) IOMs 30000 - Non-members 35000 NSMs 44000 - Students 14000

On EurophysNet at http://epswww.epfl.ch/conf/eps10.html 